\section{AROUND THE WORLD: HALLOWEEN}

\section{USA}

Halloween is the 3rd most widely celebrated holiday in the USA, behind Christmas and Thanksgiving. Around $\$ 7.4$ billion is spent each year and it is estimated that well over $\$ 2$ billion of that is spent on sweets alone. Trick or treating's roots are believed to have stemmed from the UK, where, in the Middle Ages, poor families would knock on doors and ask for food.

\section{China}

China's Halloween festival is called Teng Chieh and is a much healthier alternative to the American holiday. Rather than sweets, food and water are left as an offering to deceased relatives.

\section{UK}

Halloween spending increases year by year in the UK and it is now estimated that over £330 million will be spent on Halloween this year. Over $£ 150$ million of this will be spent on costumes.

\section{Mexico}

In Mexico, 31 October is the start of the day of the dead (Día de los Muertos) which is then celebrated until 2 November. Unlike the tongue-in-cheek celebration in the USA, the Día de los Muertos is a time of remembrance.

\title{
NOTHING HAS CHANGED
}

The British Dental Association (BDA) has responded to the launch of new consultation from the General Dental Council, suggesting a freeze in professional fees.

In 2014, the BDA defeated the General Dental Council in the High Court over a flawed fees consultation. The court, however, declined to reverse the 55\% increase that emerged from that consultation.

The GDC remains the most expensive healthcare regulator in the UK - at $£ 890$ its annual retention fee is more than twice the average professional fee - and it was recently identified as the worst performing regulator by the Professional Standards Authority in its annual performance review.

Mick Armstrong, Chair of the British Dental Association said: 'Today the General Dental Council has announced a consultation on not changing their fees. We hope they aren't expecting us to take any comfort from this, as for 40,000 dentists 'business as usual' means another year shackled to the most expensive, and least effective health regulator in Britain.

'This latest announcement shows nothing has changed. Dentists are still paying double the average for UK health professionals. Registrants are still on the receiving end of the same one-sided conversation from a cavalier regulator, which continues to ignore its own failings.

'What we've not seen is any real willingness from a failed regulator to get on top of its day job, and to finally draw a line under years of mission creep. For our part we will be subjecting these numbers to forensic scrutiny. We encourage all colleagues to have their say, so we can see what GDC's commitment to 'transparency' and 'openness' really means.'

\section{ALUMNI UPDATE}

Membership of the Bristol Dental Alumni Association, which exists to support the school and students, both past and present, recently reached 1,000 . Following a successful centenary meeting in November 2012, £60,000 was raised by the Association for a much needed refurbishment of the school's lecture theatre.

The Association has recently replaced its printed annual newsletter with emailed versions. If you are a Bristol dental graduate and have not received it then we most likely do not have your current email address.

To be included, just send us a note via the contact form found at www.bristoldentalalumni.co.uk/contact-us/ stating your year of graduation and we'll add you to our list.

\section{T-APPING INTO YOUR KNOWLEDGE}

Brush DJ, the only evidencebased, free, NHS approved app that motivates an effective self-care oral hygiene routine by playing two minutes of the user's music, is looking for your views and input.

Dentist, developer and NHS Innovation Accelerator Fellow, Ben Underwood wants your feedback on the app. What improvements would you like to see? What features do you like? What

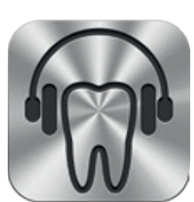
don't you like? What changes would you make to Brush DJ to take it to the next step?

Leave your feedback on the website www.brushdj. com, via email info@brushdj. com or via Twitter @BrushDJ or on Facebook. 